\title{
Study of Etiological factors, mycological profile and treatment outcome of Otomycosis
}

\author{
Prasanna V'1, V M Hemlata katiyar ${ }^{2}$, I. Kannan ${ }^{3}$ \\ ${ }^{1}$ Dr Vincent Prasanna, Associate Professor, Department of ENT, ${ }^{2}$ Dr V M Hemlata Katiyar, Assistant Professor, Department \\ of ENT, ${ }^{3}$ Dr I. Kannan, Assistant Professor, Department of Microbiology, all are affiliated to Tagore Medical College and \\ Hospital, Rathinamangalam, Chennai, Tamil Nadu, India
}

Author for correspondence: Dr Vincent Prasanna, Associate professor, Department of ENT, Tagore Medical College and Hospital, Rathinamangalam, Chennai, Email: vincent.prasanna@gmail.com

\begin{abstract}
Introduction: Otomycosis is a common condition encountered in ENT practice. Though it is not a serious condition it causes a lot of misery to the patient. Though there are many studies on various aspects about this disease, there are not many studies from this part of the country. Materials and Methods: 75 patients attending ENT OPD and diagnosed to have otomycosis were included in the study. Two aural swabs or whenever possible otomycotic debris scooped out using Jobson -Horne probe was obtained. From one swab, wet mount preparation in $10 \% \mathrm{KOH}$ (potassium hydroxide) solution and smear for Grams stain were prepared. The second swab / otomycotic debris was directly inoculated into SDA (sabourad's dextrose agar) medium. Results: Mycological analysis of the swab from external auditory canal has shown that Aspergillus species was the most common fungus isolated followed by Candida species. All patients were treated with regular suction clearance and 1\% clotrimazole ear drops. Conclusion: Simple measures like avoiding usage of ear buds/ unsterile material will help in prevention of otomycosis. $1 \%$ clotrimazole is effective in achieving complete mycological cure in otomycosis. Regular long term follow-up is required to effectively treat otomycosis.
\end{abstract}

Key words: External auditory canal, Otomycosis, Aspergillus, Candida, 1\% Clotrimazole

\section{Introduction}

Chronic infective disorders of the ear remain a common source of misery for the patients. Although not life threatening, otomycosis can be a frustrating condition for both the patient and the treating doctor due to the requirement for a long term treatment, regular follow up and its tendency for recurrence.

Otomycosis is a chronic superficial fungal infection that affects the deeper ear canal skin and the tympanic membrane. Unless manifested in the classical way, they tend to be misdiagnosed. Otomycosis is commonly associated with increased ear canal moisture, warmth and treatment of a bacterial infection with long term topical antibiotic therapy, which can lead to depletion of the protective cerumen layer, maceration of underlying skin, increase in ambient $\mathrm{pH}$ and a modification of the microbial flora of external auditory canal, thereby selecting for untreated organisms. A medical history of diabetes and / or an immunocompromised state may be present [1].

\footnotetext{
Manuscript received: $17^{\text {st }}$ June 2014

Reviewed: $20^{\text {th }}$ June 2014

Author Corrected: $29^{\text {th }}$ June 2014

Accepted for Publication: $17^{\text {nd }}$ July 2014
}

There are many studies to understand the common predisposing factors and causative fungi in otomycosis throughout the world. The most common organisms are Candida and Aspergillus species [2].

In a study conducted in Ludhiana, India, it was found that in patients with Chronic suppurative otitis media (CSOM), incidence of fungal infection was $16 \%$ in untreated group, $24 \%$ in patients treated with antibiotic drops and 32.5 in patients treated with antibiotics and steroids [3].

Study by Kaur R and others in New Delhi [4] showed 74.7 $\%$ of samples from clinically diagnosed otomycosis were positive. Aspergillus fumigatus (41.1\%) was commonest. Aspergillus niger in (36.9\%) and Candida was seen in 8.2 $\%$.

Chennai, India being a very humid place otomycosis is a common condition here. This study has tried to find the main predisposing factors and causative fungi in this region. In addition the effectiveness of $1 \%$ clotrimazole ear drops has also been studied.

Available online at: www.ijmrr.in 355 | P a g e 


\section{Materials and Methods}

A total of 75 patients were included in the study. A detailed history and examination were done and recorded.

\section{Inclusion Criteria}

All patients diagnosed as otomycosis based on the following criteria were included in the study.

(a) Symptoms - Itching, Pain, fullness in the ear

(b) Signs - Evidence of otomycosis on otoscopy - wet mycelial mat, dry mycelial mat, wet blotting paper appearance (or) creamy white debris.

(c) Cases of otitis externa which failed to respond to appropriate treatment in 2 weeks duration.

(d) Positive fungal culture from the aural debris.

\section{Exclusion Criteria}

All patients with diabetes and any other immunocompromised states and those on topical antifungal drops were excluded from the study.

\section{Isolation of fungi}

After a clinical diagnosis of otomycosis was made, two aural swabs or whenever possible otomycotic debris scooped out using Jobson -Horne probe were obtained. From one swab, wet mount preparation in $10 \% \mathrm{KOH}$ (potassium hydroxide) solution and smear for Grams stain were prepared.

\section{Results and Analysis}

\section{Age Distribution}

The age distribution is shown in Figure 1. It can be noted that maximum number of patients are in the age group 16-30. The youngest patient in this study was $2 \frac{1}{2}$ yrs old male child who had no previous history of otorrhoea, but the mother had tried cleaning the child's ear every day after bath with buds made indigenously. The oldest patient was 73 yrs old male with no previous history of CSOM or diabetes mellitus and he had been using canal insert (mould) type of hearing aid since 6 yrs. The study reveals that otomycosis was more common among adolescent and middle aged individuals. The age incidence is in accordance with studies of Mohanty and associates [5] - more prevalent in $2^{\text {nd }}$ and $3^{\text {rd }}$ decade of life, Khurana and associates[3] $-3^{\text {rd }}$ and $4^{\text {th }}$ decade, Chander J and others- $21-30$ yrs [6], Talwar and others-20- 27 yrs [7].

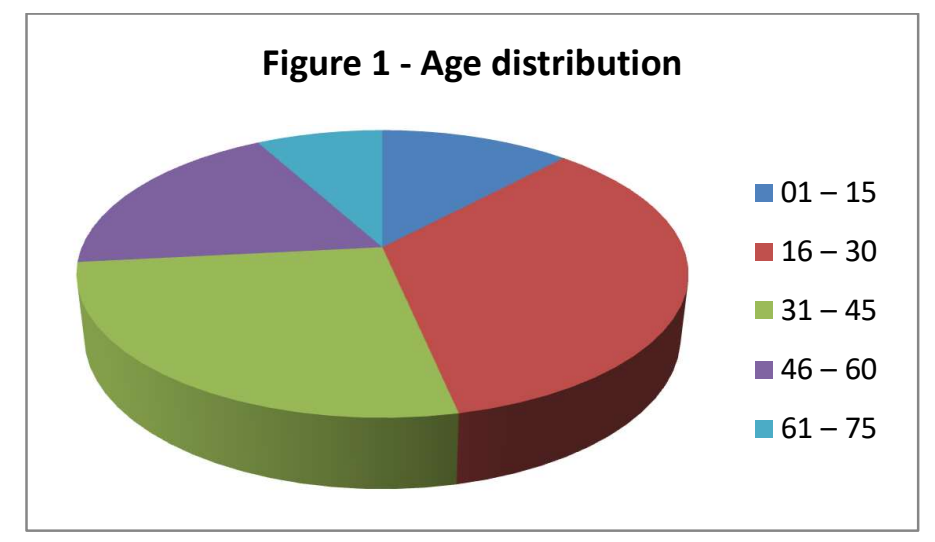




\section{Sex Distribution}

The sex distribution is shown in Figure 2. In this study, the incidence of otomycosis is more in males. This is in correlation with studies conducted by Khurana and others [3], Mohanty and associates [5], Talwar and others [7]. However studies done by Chander $\mathrm{J}$ and others [6] and Nwabuisi and Ologe [8] showed equal incidence in males and females.

The study done in Turkey by K Murat Ozcan and others [9] showed higher incidence in females (80.5 \%). However this has been attributed to the wearing of traditional head covering by females in turkey.

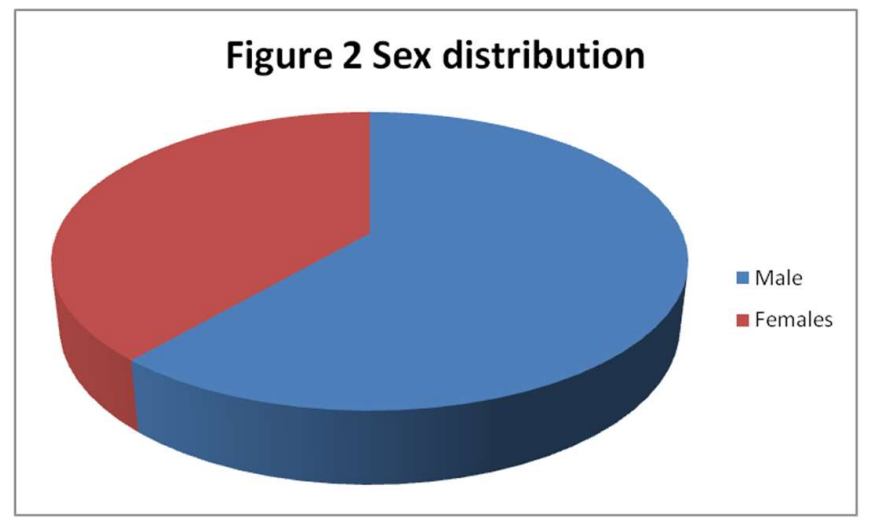

\section{Laterality Distribution}

The distribution of sides is shown in Table 1. Otomycosis in general is a unilateral disease, which is evident from this study. Maximum number of patients has been noted to have otomycosis of left ear. The predominance of left ear otomycosis has been observed in studies done by Nwabuisi and Ologe [8] in Nigeria and also by K Murat Ozcan and others [9] in Turkey.

Table 1: Laterality distribution

\begin{tabular}{|l|l|}
\hline Side & Number of patients \\
\hline Right & 31 \\
\hline Left & 36 \\
\hline Bilateral (B/L) & 08 \\
\hline
\end{tabular}

\section{Presenting Complaint}

The most common presenting symptoms were pain and Itching. This is in correlation with studies conducted by Mohanty et al [5] which showed pain in $94.4 \%$, and Itching in $92.5 \%$ patients. Also studies by Nwabuisi and associates [8], Kombilla et al [10] show otalgia and pruritis as the most common symptoms. However studies by K Murat Ozcan et al in Turkey [9] showed different observations - Pain in $54 \%$ and Itching in $95.4 \%$.

Table 2: Presenting Complaints

\begin{tabular}{|l|l|}
\hline Complaints & Number of ears \\
\hline Pain & 66 \\
\hline Itching & 63 \\
\hline Fullness & 47 \\
\hline Discharge & 37 \\
\hline Tinnitus & 28 \\
\hline
\end{tabular}

\section{Predisposing Factors}

The results are shown in Table 3. Use of the unsterile materials, which varied from safety pins, hairpins, matchsticks, pens, and refills to unsterile buds, was most common predisposing factor. Chronic suppurative otitis media (CSOM) is the second common predisposing factor. Water entering the ear while taking bath, swimming or by syringing for wax removal was the third common factor. 
These results are in accordance with study done by Mohanty et al [5], which showed ear cleaning with sticks in $75.9 \%$ as the predisposing factor and study by K Murat Ozcan et al [9] which showed only $27.6 \%$ to have had swimming in pool / sea and $23 \%$ to have had a Spa- bath prior to infection.

Table 3: Predisposing Factors

\begin{tabular}{|l|l|}
\hline Factors & Number of ears \\
\hline Buds/Unsterile Material & 65 \\
\hline CSOM & 30 \\
\hline Water Entering the ear canal/ swimming / syringing & 23 \\
\hline Narrow EAC & 21 \\
\hline Traumatic Perforation & 18 \\
\hline $\begin{array}{l}\text { Previous Surgery (MRM, } \\
\text { Tympanoplasty) }\end{array}$ & 05 \\
\hline
\end{tabular}

\section{Fungal Species}

Fungi isolated in this study are shown in Figure 3. Aspergillus Niger has been observed as the most common isolate in various studies by Mohanty et al [5], Chander J and others [6], Nwabuisi and Ologe [8], Ozcan and others [9], Kombilla et al [10], Tisner $\mathrm{J}$ and associates [11] and Oliveri S et al [12].

However studies by Kurnatowzki and Filipiak [13] showed Candida as the commoner isolate. It has been observed that Candida is commoner in temperate climate. Aspergillus species has been isolated from the air and house dust. Beany and Broughton [14] found that Aspergillus species produce antibiotics, which eliminate bacterial competitors. This could be attributed to the fact that Aspergillus is commoner than candida in the isolates.

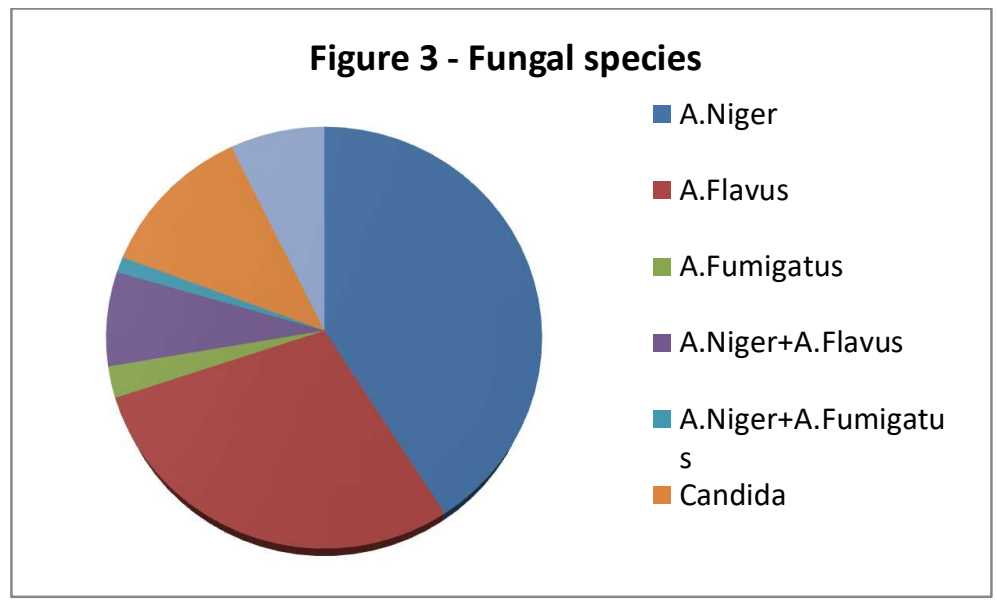

Treatment and Response

The treatment and response are shown in Table 4. In this study, $1 \%$ clotrimazole was used as the topical therapy after thorough suction clearance of ear canal. 80 out of 83 ears were cured (culture negative) at the end of 4 weeks. The three patients who showed positive culture at the end of 4 weeks had poor compliance and were not regular in follow-up. Even in these three ears mycological cure could be achieved with continued treatment for two more weeks.

These results correlate well with the results of Chander J and associates [6] and Mohanty et al [5] who showed effectiveness of clotrimazole and miconazole topical applications respectively in the treatment of otomycosis. Stern JC and associates [15] showed $1 \%$ clotrimazole to be very effective in otomycosis in vitro. 
Table 4: Treatment and Response

\begin{tabular}{|l|l|}
\hline Time period & Number of ears \\
\hline 03 Weeks & 72 \\
\hline 04 Weeks & 08 \\
\hline 06 Weeks & 03 \\
\hline
\end{tabular}

\section{Discussion}

Otomycosis contributes about $10 \%$ of all otitis externa. Conley and others have noted that ear canal provides all growth requirements for fungi [2]. Trauma to the canal skin is one of the predisposing factors to otomycosis because it helps in fungal colonization as well as Subepidermal invasion. Presence of water in the deep meatus, macerates the canal skin and alters the $\mathrm{pH}$ of canal in favour of fungal colonization. Senturia and associates [16] have described several contributory factors in addition to effects of heat, humidity and trauma. They found that absence of protective coating of cerumen, neutralization or alkalization of the canal impairs the natural ability to ward off bacterial or fungal contamination

Oliveri and associates [12] and Mugliston and $\mathrm{O}$ ' Donoghue [17] had noted in their study that there has been no significant increase in the incidence of otomycosis since the wide spread use of topical preparations began, over 20 years ago. From this study it can be understood that self induced trauma is one of the common predisposing factors which can be easily avoided.

As many as 61 different species of fungi have been identified in the clinical disease process in related studies but the most common organisms are Candida and Aspergillus species. Various studies reveal that distribution of fungi differs from temperate to tropical climate. However Candida and Aspergillus species are the predominant ones. In the present study aspergillus followed by candida remain the common isolates.

The effectiveness of topical broad spectrum antifungal is well documented $[5,8,15,18]$. Murat Ozcan and others [9] had shown that regular suction cleaning with $1 \%$ Tioconazole Cream local application in addition to $4 \%$ boric acid solution in stubborn cases was effective in the treatment even in mixed infections.

The role of systemic amphotericin B is only in those rare cases of invasive aspergillus otomycosis as was reported by Beackley LS et al [19]. In the present study regular suction cleaning with $1 \%$ clotrimazole has been effective in achieving complete mycological cure in all patients.

\section{Conclusion}

To conclude, it is suggested that

1. Patient education regarding unnecessary use of ear buds will be effective in prevention of otomycosis.

2. Aspergillus and Candida are the most common species of fungi isolated.

3. $1 \%$ clotrimazole is effective in achieving complete mycological cure in otomycosis caused by these organisms.

4. Regular long term follow-up is required to effectively treat otomycosis.

\section{Acknowledgements}

We would like to thank Dr D Elango, Assistant professor and Dr Damodaran, Senior resident, Department of ENT, Tagore medical college, for their valuable support. We also like to thank the technical staff of the department of ENT and Microbiology, Tagore medical college for their support in data collection and recording.

\section{Source of support: None}

\section{Conflict of interest: None}

\section{References}

1. Dennis J Bojrab, MD,Thomas Bruderly,DO,Yazzer Abdul Razzak. Otitis externa. OCNA, 1996; 5 : 774

2. Conley JC. Evaluation of fungus disease of the external auditory canal. Arch otolaryngol 1948; 47:721-745.

3. Kurana AS, Kanta Shashi \& Kumar Suresh. Incidence of fungal infection in CSOM. Indian Journal of otology 1998; 4(3): 121-123.

4. Kaur R, Mittal N, Kakkar M, Agarwal AK, Mathur MD. Otomycosis-A clinico-mycological study. Ear Nose Throat J 2000; 79(8): 606-609.

5. Mohanty JC, Mohanty SK, Sahoo RC, Gosh SK, Chayani N, Mallick B, KarAK. Clinico-microbial profile of otomycosis in Berhampur. Indian journal of otology 1999; 5(2): 81-83. 
Research Article

6. Chander J, Maini S, Subramanyan S, Handa A. Otomycosis -A clinico-mycological study and efficacy of mercurochrome in its treatment. Mycopathologia 1996; 135(1):9-12.

7. Talwar P, Chakrabarti A, Kaur P, Palwa RK, Mittal A, Mehra YN. Fungal infections of ear with special reference to CSOM. Mycopathologica 1988; 104(1): 4750 .

8. Nwabuisi C, Ologe FE. The fungal profile of otomycosis patients in Ilorin,Nigeria. Niger J Med 2001; 10(3) 124-126.

9. K Murat ozcan MD, Muze ozcan MD, Aydin karaarslan MD, Filiz karaarslan MD. Otomycosis in Turkey - Predisposing factors, aetiology and therapy. The J Laryngol Otol 2003;117:39-42.

10. Kombilla M, Gomez diaz M, de Bievre C,Crepet G, Debrie JC,Belembaogo E, Richard Lenoble D.Fungal otitis in Liberville-Study of 83 cases. Bull Soc Pathol Exot Filiales 1989; 82(2): 201-207. (Original article in French).

11. Tisner J, Millan J, Rivas P, Adiego I, Castello A, Valles H. Otomycosis and topical application of thiomerosal-A study of 152 cases. Acta Otorrhinolaryngol Esp 1995; 46(2): 85-89.
12. Oliveri S, Capello G, Napolitano MG, Triolo C, Grillo C. Otomycosis-Aetiology and analysis of predisposing factors. Boll Ist Sieroter, Milan, 1984; 63(6): 537-542. (Original article in Italian).

13. Kurnatowski P, Filipiak A. Otomycosis -Prevalence, clinical symptoms, therapeutic procedure. Mycoses 2001; 44(11-12): 472-479.

14. Beany GPE, Broughton A. Tropical otomycosis. J Laryngol Otol 1967; 81:987-997.

15. Stern JC, Shah MK, Lucente FE. In vitro effectiveness of 13 agents in otomycosis and review of literature.Laryngoscope 1988; 98: 1173-1177.

16. Senturia BH, Marcus MD, Lucente FE. Diseases of the external ear.New York, Grune\& Stratton, 1980.

17. Mughliston T, O'Donoghue G. Otomycosis-A continuing problem. J Laryngol Otol 1985; 99:327-333.

18. Marsh RR, Tom LWC. Ototoxicity of topical antimycotics - Presented at annual meeting of American academy of otolaryngology and head \& neck surgery; 1987.

19. Beackley LS, Betts RF, Parkins CW. Atypical invasive external otitis from Aspergillus. Arch Otolaryngol head \& neck surg 1988; 114:1024-1028.

\section{How to cite this article?}

Prasanna V, V M Hemlata katiyar, I. Kannan. Study of Etiological factors, mycological profile and treatment outcome of Otomycosis. Int J Med Res Rev 2014;2(4):355- 360. doi:10.17511/ijmrr.2014.104.14 